\title{
Vira logo a página! Mediação de leitura e processo de criação de livro de imagem
}

\section{Turn the page! Reading mediation and the process of creation of a picture book}

https://doi.org/10.34112/2317-0972a2016v34n66p93-110

\section{Hanna Talita Gonçalves Pereira de Araujo ${ }^{1}$}

RESUMO: Este artigo discute o processo de criação do livro de imagem no que tange a sua especificidade narrativa, tendo como foco a mediação da leitura. Propõem-se como material de análise imagens partilhadas em dinâmica de leitura realizada com um grupo de crianças pré-escolares e um artista. As imagens fazem parte de uma narrativa visual construída na interlocução entre o artista e essas crianças. As dificuldades de leitura e expectativas de continuação dão-nos indícios de como as crianças realizam a leitura das imagens. Por outro lado, evidenciam-se algumas expectativas dos autores em relação à leitura, as quais, por vezes, não correspondem ao previsto. PALAVRAS-CHAVE: Livro de imagem; processo de criação; mediação de leitura de imagem.

ABSTRACT: This article discusses the process of creation of a picture book according to its specific narrative, focusing on reading mediation. We have proposed the analysis of the images shared in a reading workshop with a group of preschool children and an artist. The images are part of a visual narrative constructed in the dialogue between the artist and these children. Reading difficulties and continued expectations give us clues of how children read images. On the other hand, they show part of the authors' expectations concerning reading, which sometimes do not correspond to the readers.

KEYWORDS: Picture book; process of creation; image reading mediation.

1. Universidade de São Paulo, São Paulo, SP, Brasil. 


\section{INTRODUÇÃO}

A figura do mediador de leitura na literatura, em especial aquela destinada para crianças, é foco de interesse em diferentes áreas, abrangendo profissionais da arte, da educação, da biblioteconomia, dentre outros. Diversos também são os propósitos que permeiam a necessidade de mediar o processo de leitura de crianças. Mas, e se o objeto a ser lido é composto somente por imagens? Qual é o papel desse mediador na condução da leitura e quais são seus objetivos, quando o faz? E se o mediador é o próprio autor da obra?

Este artigo aborda as questões que atravessam a mediação de leitura de livros de imagem, considerando suas particularidades narrativas. Como foco de análise, partiremos de uma das dinâmicas que compõem os dados coletados para nossa pesquisa de doutoramento, que buscou compreender os processos de criação de livros de imagem de dois artistas em interlocução com crianças. No estudo mais amplo, foram convidados dois ilustradores renomados no mercado editorial brasileiro Ciça Fittipaldi e Laurent Cardon - para que criassem uma narrativa visual (livro de imagem) em diálogo com um grupo de crianças pré-escolares da Creche/Pré-Escola Central da Universidade de São Paulo. Cada artista compôs uma história eminentemente visual a partir da leitura em etapas, obtendo a resposta das leituras e dos desenhos das crianças como elemento fomentador para a continuação da narrativa.

\section{O LIVRO SEM}

O livro de imagem é um tipo de produção editorial que tem como característica primordial a narração pela imagem. É considerado, principalmente, como um objeto destinado às crianças que ainda não são alfabetizadas ou que estão em processo de aquisição de escrita. Para constatar este fato, basta procurá-los em livrarias e bibliotecas, assim como nos editais governamentais. Essa concepção de que o livro sem texto é, sobretudo, para crianças que não leem texto escrito, parte do pressuposto de que elas conseguem ao menos ler as imagens. Porém, a suposição de que as imagens podem ser lidas automaticamente é um equívoco e está pautada numa falsa relação, como nos aponta Sophie Van der Linden (2008, p. 7, tradução nossa):

Podemos ser professores ou bibliotecários, ter mais de vinte anos de experiência e não saber ler um livro de imagem. Ler no primeiro sentido de decifrar, da denotação. 
Isso não é vergonhoso, principalmente por entender que um livro de imagem exige o conhecimento de códigos tão específicos como para combinar o be-a-bá.

É inegável a relação que as crianças têm com as imagens. Comenius, considerado como o autor do primeiro livro ${ }^{2}$ feito intencionalmente para crianças, no século XVII, já tinha consciência do poder que as imagens têm sobre as crianças, considerando que as imagens são para elas a linguagem mais inteligível. É necessário considerar que as crianças têm disposição para interpretar os elementos visuais e têm consciência de que as imagens têm uma estrutura lógica. Téo ${ }^{3}$, de 5 anos, disse que "no livro sem palavra a gente imagina o que a pessoa pode falar. A gente pode pensar o que a pessoa está tentando falar. A pessoa, o cara que fez o livro".

Sara, autora francesa de diversos livros de imagem, defende a imagem como linguagem, mas reconhece que isso não é consensual, principalmente nas escolas:

Quando eu vou nas escolas, por exemplo, tento ensinar tanto para as crianças como para as pessoas grandes, eu tento convencê-las de que a imagem é uma língua, do mesmo modo que a língua francesa ou outra. E ela tem sua gramática e seu vocabulário. ${ }^{4}$

Inúmeros livros de imagem demostram como eles não são apenas restritos para as crianças não alfabetizadas. Cântico dos cânticos e Cena de rua, de Angela Lago; A chegada, de Shaun Tan; Revolution, de Sara, são alguns exemplos que apresentam estruturas narrativas complexas que desconcertam muitos adultos. Consideramos, desse modo, os livros de imagem como objetos que são também para crianças não alfabetizadas. Nesse sentido, os níveis de leitura se diferirão de acordo com a experiência de cada leitor.

Embora a imagem na literatura dita infantil tenha reconhecimento como um dos elementos mais importantes na composição da obra, percebemos que a constituição de um livro, desde a sua invenção, pressupõe o texto escrito.

2. Orbis sensualium pictus consistia em um dicionário bilíngue por imagens.

3. Os nomes das crianças foram alterados, buscando preservar sua identidade.

4. Trecho de fala em palestra na Ecole supérieure du Professorat et de l'Éducation na Université de Poitiers, em novembro de 2013. Disponível em: <http://uptv.univ-poitiers.fr/program/rencontre-avec-l-auteurillustratrice-sara/video/4064/rencontre-avec-l-auteur-et-graphiste-sara/index.html>. Acesso em: 31 jul. 2014. 
Neste ponto, podemos considerar brevemente a denominação do livro de imagem em outras línguas. Wordless picturebooks (inglês), livre sans mots ou sans paroles (francês) e libro senza parole (italiano) são alguns dos exemplos de como esse tipo de livro é nomeado pela falta, pela circunstância de não estar presente aquilo que esperávamos que estivesse: a linguagem escrita - terminologia que enfatiza o contrário: a não palavra -, em vez de valorizar aquilo que lhe é específico: a narração exclusivamente pela imagem. Renato Moriconi (2014), sobre a questão da nomenclatura dos livros, pontua que "a gente dá nome para as coisas e não aleatoriamente. A gente dá nome a partir do conceito que a gente tem sobre as coisas". Esse artista do livro faz referência às nomenclaturas dadas aos livros e à categorização que os editais e os prêmios criam para os enquadrar.

Nesse sentido, a concepção atual do livro de imagem no Brasil difere da de outros países. Este tipo de produção é aqui chamado de "livro de imagem" ou "livro-imagem", compreendendo este último como um objeto cuja constituição está imbricada na imagem como conjunto, na ideia de livro como desenho total. De qualquer forma, ambas as denominações brasileiras exaltam a natureza essencialmente imagética na poética da obra, considerando-o como um livro COM e não como um livro SEM.

Apesar dos desencontros em relação à constituição dos livros de imagens, autores que atuam, muitas vezes, também como artistas plásticos, comprovam que é um objeto que pode deter narrativas densas. No grupo de autores brasileiros, contamos com diversos artistas que se dedicam à criação de excelentes livros de imagem, como Angela Lago, Odilon Moraes, André Neves, Roger Mello, Graça Lima, Renato Moriconi e tantos outros. O livro de imagem permite aos artistas, que também atuam como ilustradores de textos, produzirem um objeto que associa narrativa visual e projeto gráfico, do qual eles são os autores, no sentido mais amplo que isso representa.

\section{Mediação: entre o desalento e a fruição}

A mediação de livros de imagem representa um desafio enorme para o adulto. Por diversas vezes tive a oportunidade de ouvir relatos em que bibliotecárias evitam esse tipo de livro nos momentos de leitura. Do mesmo modo, professores e pais muito bem-intencionados sentem-se perdidos ao partilhar a leitura com as crianças. 
Essa sensação diante dos livros de imagem advém da ausência de familiaridade em lidar com objetos que se baseiam em uma linguagem com que os adultos não se sentem confortáveis ou à qual não dão tanto valor. Provavelmente entre adultos admiradores das artes visuais, frequentadores de exposições, leitores experientes de histórias em quadrinhos e romances gráficos, a manipulação de livros de imagem ocorra de um modo mais fluido e instigante.

O receio em relação ao livro de imagem deriva do fato de que, muitas vezes, ele abre possibilidades de leitura em que os significados narrativos não se restringem à superfície tangível de denotação dos elementos visuais, e sua leitura pede outra disposição de tempo e observação.

$\mathrm{Na}$ leitura compartilhada com crianças - nas rodas de leituras na escola ou na leitura antes de a criança dormir -, de livros em que o texto escrito está presente, os adultos sentem-se atuantes e importantes. Fazem a leitura do texto e apontam uma ou outra imagem que têm algum tipo de relação com o escrito, viram a página e partem para a leitura de mais um texto escrito. É inegável que esse tipo de leitura funciona e tem um papel fundamental na criação de vínculos afetivos entre as crianças e a literatura. Mas o livro de imagem tem outros ditames. Dessa forma, exige outro tipo de abordagem e consequente relação.

Esse empecilho na fruição das narrativas por imagens se mostra presente tanto na mediação de leitura do adulto, quanto na leitura pelas crianças. Em minha experiência como mediadora de leitura de livros de imagem, uma das frases mais presentes é a que rendeu título ao presente texto: "Vira logo a página!". A ansiedade das crianças para o momento da virada da página não representa que elas não apreciem esse tipo de história, muito pelo contrário! Diferentemente dos livros com texto escrito, elas têm apenas a imagem como arcabouço narrativo, e na sucessão de páginas a sequência se desencadeia. E, ao final, as crianças retomam a leitura, num ir-e-vir sistemático das páginas, buscando os elos para preencher as lacunas. Além de buscarem milimetricamente outros elementos paralelos à narrativa. Desse modo, um livro de imagem é passível de inúmeras leituras.

Essa capacidade de vasculhar uma imagem e construir sentido com o que se visualiza é muito restrita, principalmente no contexto escolar. O letramento visual acaba sendo minado, primeiramente, pela ausência de importância dada à imagem, assim como pela carência desse letramento por aqueles que deveriam ensiná-los, uma vez que letramento visual é definido como a capacidade de ler e interpretar um 
conjunto de elementos visuais aprofundando nos níveis de leitura e consequente significação (DONDIS, 1997).

Reily (2003, p. 164, grifo nosso) considera que

a imagem vem sendo utilizada na escola com uma função primordialmente decorativa, de tal forma a diluir o tédio provocado pela grafia de textos visualmente desinteressantes. Com isso, despreza-se um recurso cultural que permeia todos os campos do conhecimento e que traz consigo uma estrutura capaz de instrumentalizar o pensamento.

Evelyn Arizpe e Morag Styles (2004, p. 15, tradução nossa) identificaram a mesma realidade num amplo estudo sobre leitura de imagens de livros ilustrados num contexto muito distinto, no Reino Unido: "Infelizmente nosso sistema educativo não compreende e nem aproveita a leitura de imagens como uma destreza ou capacidade". As pesquisadoras identificaram também um consenso entre as centenas de crianças participantes de que as imagens são mais interessantes que os textos. E de que um livro seria bom ainda que dele tirassem as palavras, mas que, sem as imagens, ele seria entediante, em especial para as crianças.

Assim, a maioria dos currículos escolares não favorece o aprofundamento de leitura das obras, seja pela divisão do tempo pedagógico ou por ausência de habilidades de leitura e fruição. No tocante aos livros de imagem esse fato torna-se flagrante, pois não raras vezes suas leituras atuam como estímulo apenas para a escrita textual. E isso pode ser uma parte do processo, não o único objetivo. Na leitura e na partilha da leitura de imagem, as palavras norteadoras são "fruição" e "deleite" diante do objeto artístico, buscando sentido entre o visto e o vivido, construindo relações com a arte e sendo afetados por ela.

\section{AUtor-MEdiador: O QUE VOCÊS ACHAM QUE VAI ACONTECER AGORA?}

Temos como recorte de análise no presente texto a mediação de um trecho da leitura do projeto de livro Briga de amor, ${ }^{5}$ feita por Laurent Cardon com o Grupo Caracol ${ }^{6}$.

Laurent Cardon, francês radicado no Brasil, é um artista visual que trabalha sobretudo como cineasta, mas há alguns anos se revelou como um excelente autor

5. O projeto de livro passou por finalização, está no prelo e será editado pela Editora Pandabooks.

6. A cada ano os agrupamentos da Creche/Pré-Escola Central da Universidade de São Paulo elegem um nome para representá-los, com o intuito de desenvolver a identidade de um coletivo. Caracol é o nome de uma das turmas de crianças entre 5 e 6 anos que frequentaram a instituição no ano de 2013. 
de livros de imagem e ilustrador. Conta com uma rica coleção de livros de imagem, tendo recebido diversos prêmios.

Em entrevista, explicou como passou a criar narrativas visuais:

Obviamente, para mim, o livro de imagem é uma extensão do storyboard. Não é por acaso. Trabalhei a vida inteira com animação, então trabalhei muito com storyboard. [...] Você tenta resolver tudo com imagem. É realmente uma ginástica, um trabalho. Então pra mim, o livro de imagem é realmente uma extensão do storyboard. É isso que me deu vontade de trabalhar com livro de imagem. É mais uma provocação que eu faço pra mim mesmo, até que ponto precisa de texto para contar essa história? Então eu vou puxando os limites para ver como que eu faço (CARDON, 2013).

O desafio de criar uma história que se baseie absolutamente na imagem representa para os artistas um instigante campo de pesquisa e experimentação. Incentivadas pelos editais governamentais, as editoras acabam publicando muitos livros de imagem, o que representa mais uma abertura de espaço para a imagem autoral na literatura.

A troca entre autores e crianças é uma prática cada vez mais crescente em escolas e feiras de livros. Nessas ocasiões, as crianças têm a oportunidade de ouvir os artistas sobre o ofício que envolve a produção do livro, assim como o artista tem contato com seus leitores e recebe o feedback de suas obras. $\mathrm{O}$ contato com os leitores amplia a noção dos autores de imagem no que compete à recepção dos livros e das histórias, enriquecendo tanto a produção poética quanto a destreza no ramo editorial. Renato Moriconi (2014) exemplifica a importância do contato com criança, também no que concerne à negociação com os editores:

Criança pensa diferente da maneira que vocês [as editoras] acreditam que elas pensam, sobre formato. Já ouvi dizer: "Ah, criança só gosta desse formato, não gosta daquele...". Quando você vai na escola, vê que as crianças gostam de tudo que é formato, porque as crianças são diferentes também. Tem criança que gosta desse e não gosta do outro. Tem criança que gosta de nada, tem criança que gosta de tudo. Quão mais abrangente for a linguagem, melhor.

Outra importante contribuição que os encontros com as crianças trazem para o trabalho do artista é a de dar a ele uma noção da recepção que tem a imagem, de perceber a correspondência da intenção inicial do autor com as leituras feitas. 
Laurent Cardon reconhece que a leitura das crianças o faz refletir sobre sua criação. Referindo-se à coleção sobre animais (Editora Biruta) e um recurso de quadro na composição, disse:

Eu mostrava, perguntava. Eu usei bastante nesta coleção o recurso de janelinha. Então, uma criança falou pra mim: - Ah, engraçado, ele tá numa janela. E não tem absolutamente nada que remete, fora o quadrado, dentro da ilustração. [...] Aí fiquei preocupado, ele tá vendo uma janela. Eu fiquei preocupado com minha narração. Depois não me preocupei mais. Pra mim é mais uma falta de concentração das crianças na história. Por que que vocês estão vendo aqui? Aí tinha todo tipo de reação. É bom ler tudo, e depois fazer as perguntas para as crianças. Elas enxergam outra coisa quando elas conhecem tudo. É difícil perguntar, à medida que o livro tá avançando, o que está acontecendo. Precisa ir um pouquinho mais pra frente para entender o que aconteceu atrás. E vinha todo tipo de comentário. E eu pensava, "será que eu errei?". Precisa atenção, precisa olhar! (CARDON, 2013).

Esse descompasso entre o que as crianças leem e o que os artistas acreditam que elas leem pôde ser constatado na pesquisa de mestrado (ARAÚJO, 2010), em que a intenção do artista na composição da narrativa não condiz, algumas vezes, com a leitura das crianças. Apesar do crescente encontro entre autores e leitores, o tipo de contato próximo entre eles é escasso. Isso não permite que o leitor adentre no livro e consiga fruí-lo em meio à agitação dos eventos. Para o artista, também, a quantidade de crianças não possibilita que ele se aproxime de todos, pergunte sobre os livros e suas leituras. Fica claro que o contato entre autores e leitores é extremamente favorável, gerando um aprendizado mútuo, mas acreditamos que o contato mais intimista traria melhor aproveitamento para ambos os sujeitos: crianças e autores.

Tivemos a oportunidade de confrontar crianças e artista, que têm como objeto comum um livro feito em coautoria. $\mathrm{O}$ recorte de análise corresponde à leitura da história, sendo que as crianças conheciam apenas a metade; e o restante foi mediado pelo autor.

\section{BRIGA DE AMOR}

Briga de amor é uma história por imagens que surgiu na relação entre Laurent Cardon e um grupo de 18 crianças pré-escolares, mediadas pela professora/doutoranda em artes visuais. A dinâmica completa entre Laurent Cardon e o Grupo 
Caracol, que é analisada na tese de doutorado (ARAÚJO, 2016), consistiu em três mensagens escritas e duas etapas de leitura.

O artista havia solicitado que as crianças escolhessem dois animais como personagens, elencassem as características de cada um, assim como a 'situação' que seria o mote da narrativa. As crianças, após longo debate, elegeram Caracol, Joaninha e Esquilo; e a situação, 'briga de amor'. As crianças, em pequenos grupos, sistematizaram as principais características dos diferentes animais como, por exemplo, as do Esquilo:

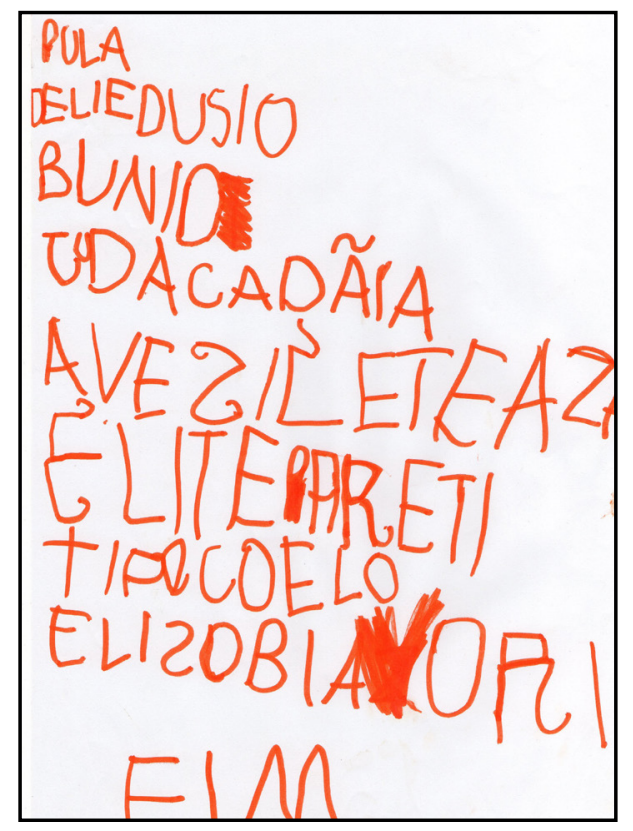

Figura 1. Escrita coletiva sobre as características do personagem Esquilo7, 2013. Fonte: Foto da autora

O primeiro conjunto de imagens elaboradas depois dessa escrita coletiva foi enviado pelo artista para a pesquisadora/mediadora, que as leu com as crianças. A dinâmica de leitura das imagens e as opiniões sobre a continuidade foram videogravadas, transcritas, e esses diálogos enviados para o artista, assim como os desenhos

7. Pula, Dentucinho, Bonito, Junta castanha, Às vezes voa, Tipo coelho, Ele sobe em árvore, Fim. 
das crianças sobre a história. A metodologia pedia que o artista esperasse esses materiais para dar prosseguimento à construção da narrativa.

O segundo e último grupo de imagens foi lido em conjunto com Laurent Cardon, em dezembro de 2013, na sala do Grupo Caracol, na Creche/Pré-Escola Central da USP.

O encontro era uma surpresa para as crianças, mas, ao se depararem com um homem alto e com óculos verdes, com sotaque, lembraram-se da foto que acompanha os outros livros do autor. Laurent Cardon era uma personalidade que acompanhava o cotidiano das crianças.

Laurent Cardon fez referência à narrativa visual como "Nosso livro". Sua fala buscou construir um sentido de pertencimento entre sua criação e as opiniões dos leitores, estabelecendo coautoria com dizeres como "eu li tudo o que vocês falaram", e "vocês fizeram uma grande parte do trabalho e eu fiz outra grande parte do trabalho".

As crianças demonstraram muito interesse na fala do autor e concentraram sua atenção no momento em que o autor desenhava: "Ele desenha muito bem". Em sua fala, Cardon expôs seu processo de criação, tomando como base a narrativa. Fez diversas perguntas disparadoras, buscando aguçar a leitura: "E vocês têm ideia de quem ganha nessa história? O que vocês acham que tem o Esquilo?, O que a gente sabe do Caracol?" Desenhava e escrevia ideias e sugestões das crianças. 


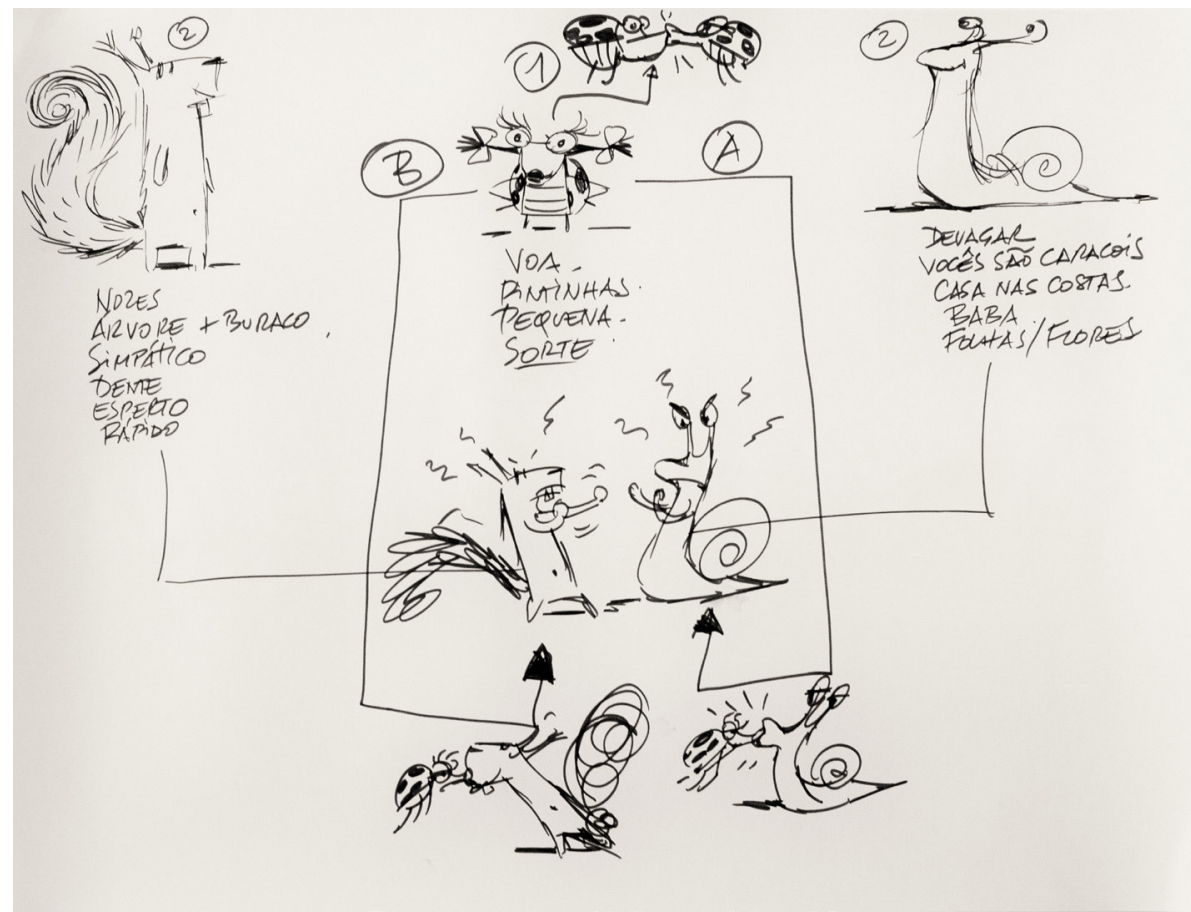

Figura 2. Painel desenhado durante a dinâmica. Fonte: Laurent Cardon, 2013

$\mathrm{O}$ esquema desenhado pelo artista no momento da leitura dava indícios de como seria o final da história, mas, apesar disso, nenhuma criança o considerou como uma finalização possível. Elas estavam convictas de que o Caracol "ganharia" a briga pela Joaninha, apesar dos beijos entre o caracol, o esquilo e um "Joaninho".

Em seu painel Laurent elaborou, aos olhos das crianças, um esquema da história que criou, a partir dos elementos por elas dados. Dizia: "Porque vocês pediram para criar uma briga de amor. Primeiro, eu falei: briga de amor de quem com quem? Podia ser uma esquilo fêmea, com joaninha e caracol macho brigando pela esquilo fêmea". Isabel rebateu, dizendo: "Não, eu acho melhor a joaninha ser menina". Laurent Cardon buscou inserir outras possibilidades, considerando joaninha macho, caracol fêmea, mas ele criou a narrativa de acordo com as características levantadas pelas crianças: "Por que a gente acha que joaninha é fêmea, mas tem macho também. Mas na nossa história a joaninha é fêmea, e são os dois que vão se apaixonar por ela". Com essa série de falas o autor demonstrou para as crianças os meandros da criação de histórias: "Anoto tudo quando as ideias vêm. É sempre assim antes de criar uma história. Tem que 
juntar tudo o que a gente sabe. É assim que eu faço" (CARDON, 2013). Expôs como os elementos se entretecem para a criação de expectativas, como cada personagem tem de ter suas características, etc.

A leitura coletiva permite muitas contribuições entre os sujeitos. Percebemos cotidianamente como a fala de cada criança incita a leitura e gera questionamentos. No entanto, o aglomerado de crianças faz com que, por vezes, algumas falas muito pertinentes sejam esmorecidas pelo ruído provocado por alguém.

No levantamento das características dos animais, por exemplo, Laurent Cardon escreveu referente ao Caracol - casa nas costas - e comentou: "Isso éo mais interessante!". No entanto, com o alvoroço das crianças na sala, a voz de João não foi ouvida: "O Esquilo não pode levar a casa nas costas". Mas Laurent não escutou, pois outras crianças falavam ao mesmo tempo. A fala de João ia de encontro com a do artista, levantando um contraponto muito interessante entre Caracol e Esquilo, abrindo outras possibilidades. Quando Laurent refez a pergunta, João formulou outra fala e disse: "Eu gosto quando ele aposta corrida!". E Laurent identificou a origem da fala em um filme de animação popularizado no cinema e respondeu: "Mas isso você tá falando do filme que lançaram. O que a gente sabe sobre Caracol antes de ter esse filme?". Essa breve situação pontua como algumas falas se esvaem na mediação de leitura. Esse momento passou despercebido para os adultos presentes e só pôde ser notado ao rever a dinâmica videogravada. $\mathrm{O}$ ruído, muitas vezes, impede que o adulto-mediador ouça uma fala mais tímida, assim como uma situação mais tumultuada não cria ambiente para que uma criança mais retraída se sinta tranquila para exprimir-se.

Quando Laurent elencou as características da joaninha, as crianças gritaram em uníssono: "Ela voa!". Para surpresa do artista: "Nossa, é a primeira coisa que vocês pensam? Joaninha traz sorte!", foi a afirmação de Laurent Cardon, referendando uma crença francesa. No entanto, as crianças não entenderam sua fala e, quando ele tentou explicar, perguntando o que acontece quando uma joaninha pousa em alguém, as crianças disseram que ela faz cócegas, não relacionando "sorte" com Joaninha. Esse breve exemplo demonstra como os autores e os leitores podem ter pontos de partida distintos na construção dos significados.

Ao mostrar a narrativa projetada no telão, Laurent disse às crianças que olhassem para a imagem e imaginassem uma linha divisória, simulando a dobra da página. Mostrou para as crianças o protótipo do livro, a que os autores chamam de 'boneco', dizendo: "Eu fiz um livrinho. Quando a gente faz um projeto, a gente faz um livrinho. E eu não vou mostrar a capa", criando uma expectativa nas crianças, que pediram: 
"A gente quer ver a capa!!!". Laurent Cardon esclareceu: "Só no final, vocês vão me ajudar para ver se eu fiz a capa certa". Mais uma vez podemos perceber como o artista dá para as crianças a perspectiva da criação e da complexidade na construção das imagens, dizendo sobre as diversas escolhas que têm que ser feitas ao produzir.

A narrativa visual era composta por 25 imagens, de modo que não caberia a análise neste texto. Nós nos ateremos àquelas que geraram mais discussões e que exigem dos leitores habilidades distintas.

Conquistar a Joaninha é o objetivo tanto do Esquilo quanto do Caracol. Nesta imagem (Figura 3 ) podemos perceber que existe uma troca entre dois personagens. Para esse grupo de crianças de 5 e 6 anos, a disposição dos personagens em diferentes posições em uma mesma imagem não representa mais uma dificuldade de leitura. A cadência entre as figuras (cima e baixo) pode ter contribuído para a leitura, pois em outras leituras com algumas dessas crianças elas entendiam os duplos como diferentes personagens.
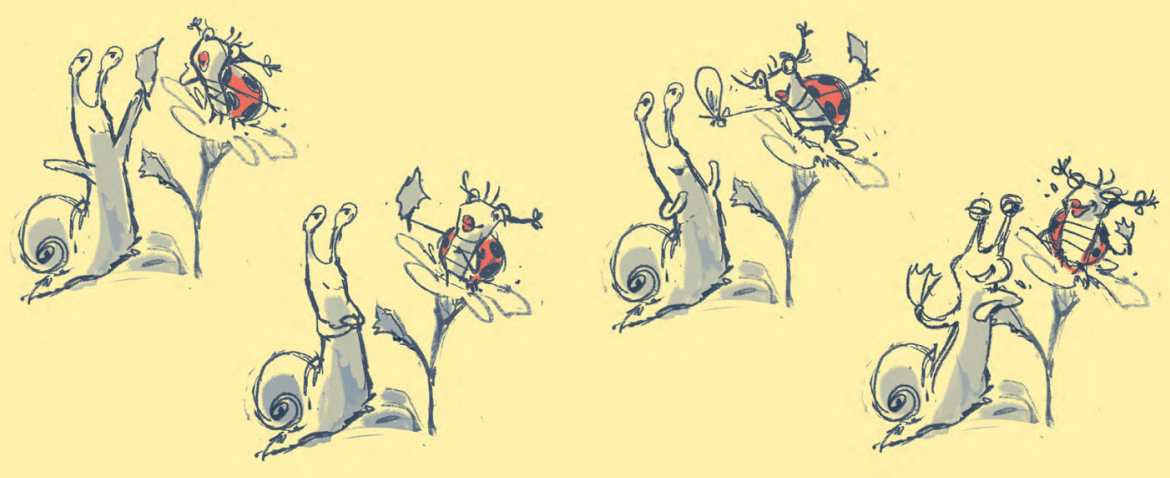

Figura 3. Quarta página dupla, Briga de amor. Fonte: Laurent Cardon, 2013 
Este é um recurso bastante utilizado nas composições de livros de imagem, influenciado pelo desenho animado e pelas HQs, que busca dar a sequência de ações e aproveitar espaço.

Nesta quarta página Laurent se detém e conclui que as crianças conseguiram compreender esta transição. E pergunta: "Quem se apaixonou, se interessou pelo outro?". Ao que as crianças, para surpresa do autor, respondem: "A Joaninha". Na construção da história, a Joaninha tem um ar misterioso, e as relações entre os personagens ainda correspondem a um repertório que as crianças não compartilham. Laurent defendeu: "Eu acho o contrário. A gente ainda não sabe o que a Joaninha está pensando". E, verbalizando, buscou reconstruir seu raciocínio sobre a imagem (Figura 3: "Ele deu uma folha e ela retribuiu. Ela dá o que para ele?". João olha a imagem e responde: "Um saco". Essa foi a percepção imediata de João, que estava muito atento à narrativa. As demais crianças o observam e refletem sobre sua fala. Surpreso diante da resposta, o autor responde: "Ops, tudo bem, esse desenho eu fiz rapidinho, mas vamos tentar entender o que ela tá dando pra ele. Vamos lá, ele tá dando uma folha, e ela tá dando...". As crianças ficaram em silêncio, pois de fato não compreenderam o desenho ou a troca entre os personagens, ainda que apenas João tivesse verbalizado. Após a pausa, o mediador conclui: "Ah, vocês não entenderam". Juliana, a mais velha do grupo, com 6 anos completos, responde, tímida: "Uma pétala...". Laurent, aliviado, confirmou. Mas se ateve no detalhe para que as crianças compreendessem: "Ela está sentada numa flor e está dando uma pétala. Se fosse um saco ficaria pendurado, não? Aqui não parece um saco. Tudo bem, está mal desenhado!".

Embora as crianças tivessem compreendido o 'flerte' entre Joaninha e Caracol dentro do contexto da narrativa, eles não perceberam um elemento de ligação importante entre os dois: compartilhavam a mesma alimentação. A estruturação da imagem não favoreceu a compreensão das crianças para a sutileza dos gestos.

$\mathrm{O}$ jogo proposto pelo artista para a conquista da Joaninha instiga as crianças e as surpreende pela alternância entre os dois conquistadores. A todo momento eles acreditavam que havia acabado a história. Téo, logo que viu a imagem em que o Caracol beijava a Joaninha, gritou: "Ele deu flor e ela deu um beijo na boca. Na boca, eca! E agora eles vão ficar felizes". Mas a narrativa continuou, criando maior expectativa.

O balão, recurso muito utilizado pela linguagem dos quadrinhos para a inserção de diálogos, inserido na dobra da página, foi logo compreendido pelas crianças. Essa constatação das crianças nos surpreendeu, pois o balão estava direcionado à esquerda, culminando na dobra da página, estando o locutor ausente. Laurent 
perguntou, na leitura dessa imagem, quem estaria assobiando. As crianças prontamente responderam: "O Esquilo!", o que surpreendeu o autor, pois era uma imagem de difícil leitura. A composição apresenta o casal Joaninha e Caracol em dois distintos momentos, assim como o balão de assobio entre as duas figuras. É importante, para a leitura dessa imagem, a habilidade de abstração da margem ou dobra da página como um segundo plano narrativo.
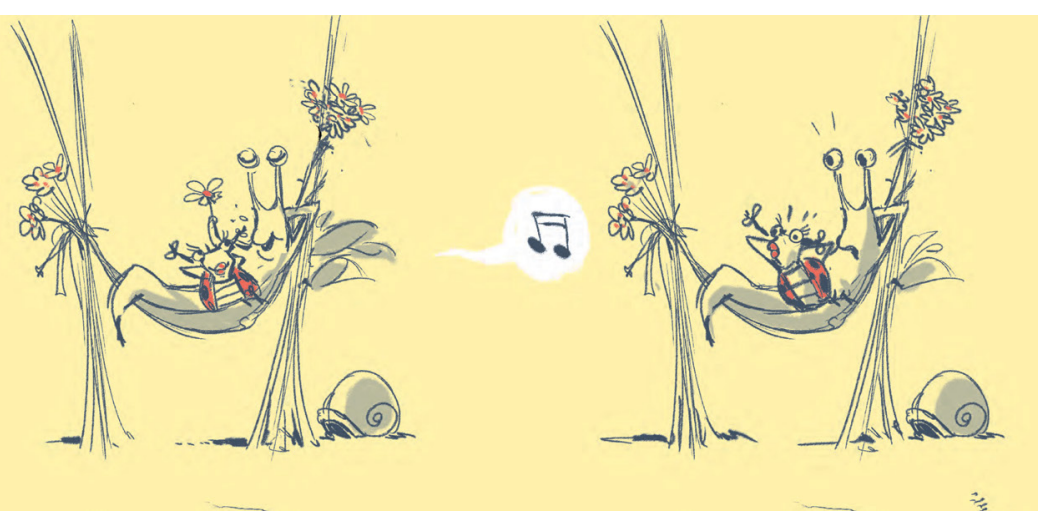

Figura 4. Décima primeira página dupla, Briga de amor. Fonte: Laurent Cardon, 2013

As crianças perceberam o detalhe de que o Caracol tira a concha ao deitar-se na rede. E comentaram que iria quebrar a concha e que, desse modo, ele havia se tornado uma lesma.

$\mathrm{O}$ autor-mediador buscou gerar reflexões sobre as relações estabelecidas entre os personagens: "Vocês fariam a mesma coisa? [Quando Esquilo e Joaninha foram embora] Falaram tchau pro Caracol. Sacanagem, né?". 

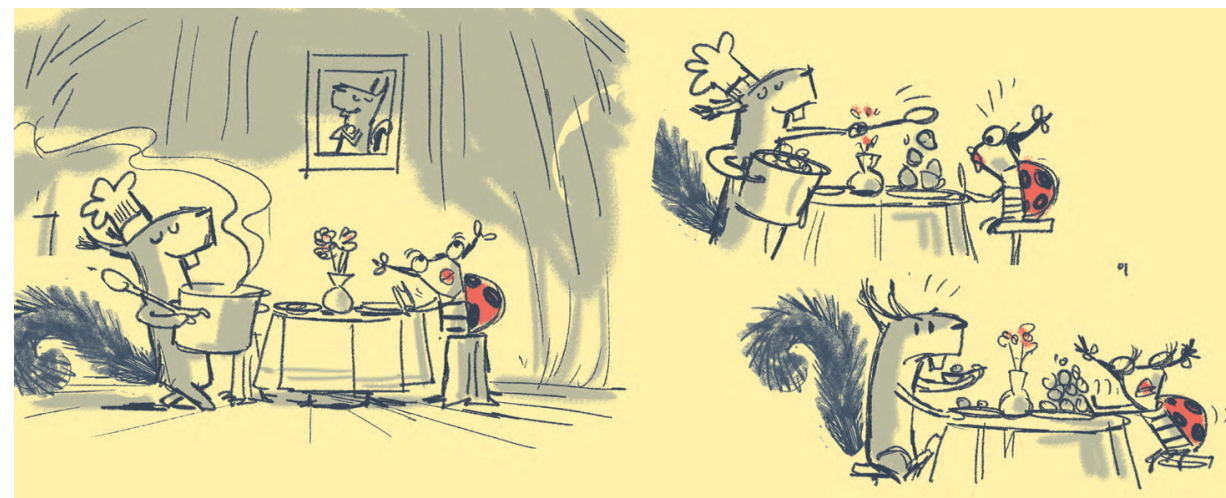

Figura 5. Décima quarta página dupla, Briga de amor. Fonte: Laurent Cardon, 2013

Em outra imagem que trazemos (Figura 5), buscamos evidenciar as expectativas do autor quando da composição da imagem e as leituras que as crianças fazem. Nesta imagem, a Joaninha foi conhecer a casa do Esquilo após ter abandonado o Caracol. Para as crianças, a primeira impressão é o tamanho da casa: o que no exterior era um buraco na árvore tornou-se uma grande casa. Téo disse: "Ele fez uma sopa de nozes mas ela não gostou!". Para o artista criador da imagem, suas expectativas eram de que as crianças percebessem a vaidade do Esquilo: "Tem uma foto dele na parede, quer dizer que ele se acha o máximo". Além disso, outra informação dessa imagem que foi percebida pelas crianças em relação à comida foi que a Joaninha não gosta de nozes. Laurent criou, também, expectativa nas crianças sobre o Caracol: "A gente tá apaixonado pelo Caracol, porque esse Esquilo não vale nada!".

$\mathrm{Na}$ sequência das imagens em que se apresenta o cotidiano da Joaninha com a Esquilo, as crianças identificam uma situação de compaixão do Caracol para com a Joaninha. A Joaninha estava sendo explorada pelo Esquilo, e isto era muito injusto, de acordo com as crianças (figura 6). Lembramos que, para o Grupo Caracol, o herói da história era o personagem homônimo. $\mathrm{O}$ autor criou esta situação, buscando construir uma expectativa em relação ao Caracol e à atitude que ele teria. 

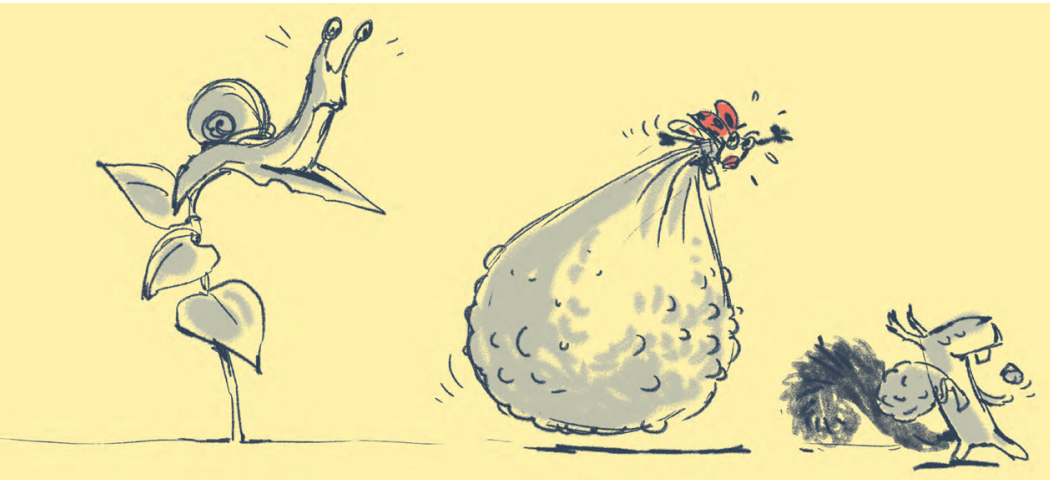

Figura 6: Décima sexta página dupla, Briga de amor. Fonte: Laurent Cardon, 2013

O artista conseguiu despistar as suposições, revirando a sequência esperada. Laurent Cardon disse que a expressão do Caracol diante da situação da Joaninha não era de piedade, mas que revelava que ele havia tido uma ideia: explorar a Joaninha também, o que se passou na continuação da narrativa. Para a leitura desta imagem, seria necessário avançar algumas páginas e, após conhecer alguns elementos posteriores, compreender determinadas atitudes anteriores.

\section{É ASSIM QUE SE CRIA UMA HISTÓRIA: AS CONSIDERAÇÕES FINAIS}

A relação que o artista Laurent Cardon teve com a construção da Briga de amor foi intensa. Demonstrou ter escutado as crianças em suas extravagantes sugestões assim como nas características construídas. Como bom criador de histórias, surpreendeu-nos com uma reviravolta, nos demonstrando que nem tudo é o que parece.

As crianças, durante os quatro meses de gestação da história, conviveram cotidianamente com a narrativa e com Laurent, como era conhecido por eles, através de seus livros. Demonstravam-se muito habilidosos na compreensão dos diferentes tipos narrativos que partilhávamos nos momentos em grupo. Eram ávidos por narrativas de múltiplos tipos: por imagens, orais, teatro de sombra, marionetes, etc. Percebemos, ao longo do ano, que a idade é um fator fundamental de diferença na compreensão de certas sutilezas narrativas. Entre o mais novo, João, e a mais velha, Juliana, ficou evidente como a aproximação com o universo escrito amplia o repertório, incluído o visual. Ao mesmo tempo, as crianças mais novas estão mais 
desprendidas do mundo adulto e conseguem imaginar mais abertamente, característica esta tão cara para a leitura das diversas obras.

A intenção de Laurent Cardon era dar a dimensão do métier do autor de livro de imagem: "É assim que se cria uma história! Vocês viram como fazer uma história pode ser complicado? Vocês deveriam tentar fazer também...”. Não há dúvida de que este encontro com o artista reverberou na experiência e na relação dessas crianças com a leitura de livros. Foi também na relação com o artista-autor que elas puderam ter a dimensão da complexidade da criação artística. Por outro lado, essa particular situação de criação possibilitou a Laurent o contato com os leitores de suas obras, no desalento da leitura, assim como na fruição das imagens.

$\mathrm{O}$ aprendizado adquirido com essa dinâmica indica o quanto a mediação de leituras de imagens é complexa e requer distintos atributos desse sujeito que faz a ponte entre o livro e a criança.

\section{REFERÊNCIAS}

ARAUJO, HANNA. Livro de imagem: três artistas narram seus processos de criação. Dissertação (Mestrado) - Instituto de Artes, UNICAMP, 2010.

. Processos de criação e leitura de livros de imagem: interlocuções entre artistas e crianças.

Tese (Doutorado) - Instituto de Artes, UNICAMP, 2016.

ARIZPE, E.; STYLES, M. Lectura de imágenes: los niños interpretan textos visuales. Ciudad de

México: Fondo de Cultura Económica, 2004.

CARDON, L. Entrevista concedida para Hanna Araújo. São Paulo, 2013. . Briga de amor. (No prelo).

DONDIS, D. Sintaxe da linguagem visual. $2^{\text {a }}$ ed. São Paulo: Martins Fontes, 1997.

MORICONI, R. Entrevista concedida para Hanna Araujo. Paris, 2014.

REILY, L. As imagens: o lúdico e o absurdo no ensino de artes para pré-escolares surdos. In: SILVA,

I.; KAUCHAKJE, S.; GESUELI, Z. Cidadania, surdez e linguagem: desafios e realidades. São

Paulo, Summus, 2003.

VAN DER LINDEN, S. Et si le sans avait du sens. Revue Hors Cadre[s], n. 3, p. 7-11, oct. 2008.

SOBRE A AUTORA 